\title{
Converting Traditional Water Supply Network Into 24x7, using Water GEMS to Optimize Design
}

\author{
Mukund M.Pawar, Nitin P. Sonaje
}

\begin{abstract}
Water is all-natural driving force. Entire world struggles to preserve it. Given that India is among the top 12 water poor countries, water wastage is a critical issue for us. India's population is increasing day by day and thus the demand for water is continuously increasing. This growing demand can be met through an efficient water distribution network which can be designed using modern hydraulic software such as Water GEMS. Using the Water GEMS software Pandharpur city is selected to convert existing water supply system into $24 * 7$ continuous water supply systems. The largest investment is the pipes used in the water distribution system. The design, modeling and optimization of pipes in water supply system from an economic point of view are very important. Therefore optimal pipe network design for converting existing network into $24 x 7$ water supply system networks is carried out in this paper to reduce the cost using WaterGEM software. Study of the existing water supply network system for one zone (Ambika Nagar Zone10) is initially carried out from the Pandharpur area. The effect on demand, head loss gradient, and pressure development of the forecasted population is studied. In addition, cost optimization of the pipe network for the proposed $24 x 7$ water supply system is carried out using a genetic algorithms Darwin optimization approach.
\end{abstract}

Key words: 24x7 Water Supply System, Optimal Design, Darwin Designer, Water GEMS Software.

\section{INTRODUCTION}

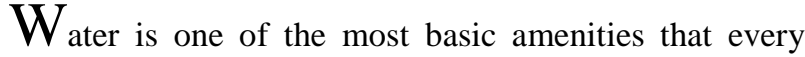
living creature requires. Besides using water for domestic needs, because man inhabited this world, water resources were the most commonly used natural system. Many beneficial uses of water include electricity generation, transportation, recreation and many other industrial uses. Reference [1] was that water distribution network has a branched and looped type of configuration of pipelines. The primary variable is flow in the network. The constraints are that demands are to be met and pressures at selected junctions in the network are to be within specified limits. The decision variables thus consists of design parameters i.e. pipe diameters, reservoir capacity, and elevation.

Reference [2] was water is the very critical resource issue of our lifetime.

Manuscript received on May 19, 2021.

Revised Manuscript received on May 26, 2021.

Manuscript published on May 30, 2021.

* Correspondence Author

Mukund M.Pawar*, Research Scholar, WIT, Solapur and Faculty, Shri Vithal Education \& Research Institute, Pandharpur (Maharashtra), India.

Dr. Nitin P. Sonaje, Principal, Government Polytechnic, Miraj (Maharashtra), India.

(c) The Authors. Published by Blue Eyes Intelligence Engineering and Sciences Publication (BEIESP). This is an open access article under the CC BY-NC-ND license (http://creativecommons.org/licenses/by-nc-nd/4.0/)
Population growth, economic development, environmental concerns and reduction in freshwater supply in the urban areas pose serious problems to water resources planning and management.

Demand for water consumption has been ever-increasing in many municipal areas, and climate change around the world simultaneously causes drought periods in some areas and at the same time flood situation in other area. Water distribution networks represent a vast infrastructure worldwide, which is critical for contemporary human existence from all social, industrial and environmental aspects. As a consequence, there is pressure on water organization's to provide customers with a continual water supply of the required quantity and quality, at a required time.

Reference [2] was the pipe network of water supply scheme represents the largest investments for the deployment. Thus, their design is to be done in such a way that the cost of networking should be minimum after satisfying the quality standards of pressure and velocity. Reference [4] was the calculation of these parameters in looped networks is performed using a simultaneous solution of a system of equations, which are primarily non-linear. The deterministic solution is difficult to obtain and usually requires the linearization of hydraulic equations, which was virtually impossible until recent computational advances.

Reference [5] was however, even with the development of software for hydraulic modeling, the design of water supply networks continued to depend on engineer's experience and expertise. To avoid this dependence and the uncertainties involved in this design process, the hydraulic model was associated with optimization techniques to obtain the network design with minimum costs.

\section{PANDHARPUR CITY}

This research is carried out for the town of Pandharpur's water supply system. Pandharpur, located in Solapur district at the bank of the Bhima River, is one of Maharashtra's most popular pilgrimage sites. Pandharpur is a tourist town in Solapur district on the banks of the Bhima River, Maharashtra, India. It is linked to all district places in Maharashtra by asphalt road. This town lies at Latitude $17^{\circ}$ 40'24.84"N Longitude $75^{\circ} 19 ' 31.38 " E$. Bhima River flowing along the town's northern boundary takes a sharp 90 degree turn and flows along the town's eastern border. During the month of ashadh (JuneJuly), in big yatra, the Vithoba temple attracts about a 0.5 to 0.7 million pilgrim. The kartiki yatra draws the second highest number of pilgrims in the area throughout the year. The rainfall in the area is normally scanty.

Published By:

Blue Eyes Intelligence Engineering

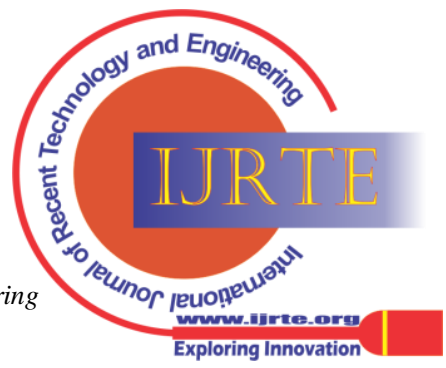


The primary source of water for Pandharpur Municipal Corporation is the Bhima River. But as far as possible we avoided expensive installation, and went for conventional methods that could prove economical. That mode will be less expensive compared to the one discussed here.

\section{ANALYSIS OF EXISTING WATER SUPPLY SYSTEM (WSS):}

The existing water supply system consists of one subterranean sump, four GSRs and 11 ESRs. These service reservoirs supply the town with water. Since the city is rapidly expanding; the city's water supply system is to be designed for $24 \times 7$ water supply to the consumer's end. Reference [6], the distribution pipe network is manualized as per Central Public Health and Environmental Engineering Organization (CPHEEO). Reference [7] was taken as Chauphala ESR is proposed to discard considering its life and serviceability. Moreover UG tank of $67 \mathrm{LL}$ will be utilized only for feeding ESRs. Therefore 10 existing ESRs are utilized and 3 ESRs are proposed as show in Fig.1. Thus total 13 operational zones are formed. The city ground levels vary from $437 \mathrm{~m}$ to $476 \mathrm{~m}$. Thus, the zoning of the entire distribution network is planned considering the topography of the city and also to fulfill the existing ESR's for its maximum capacity.

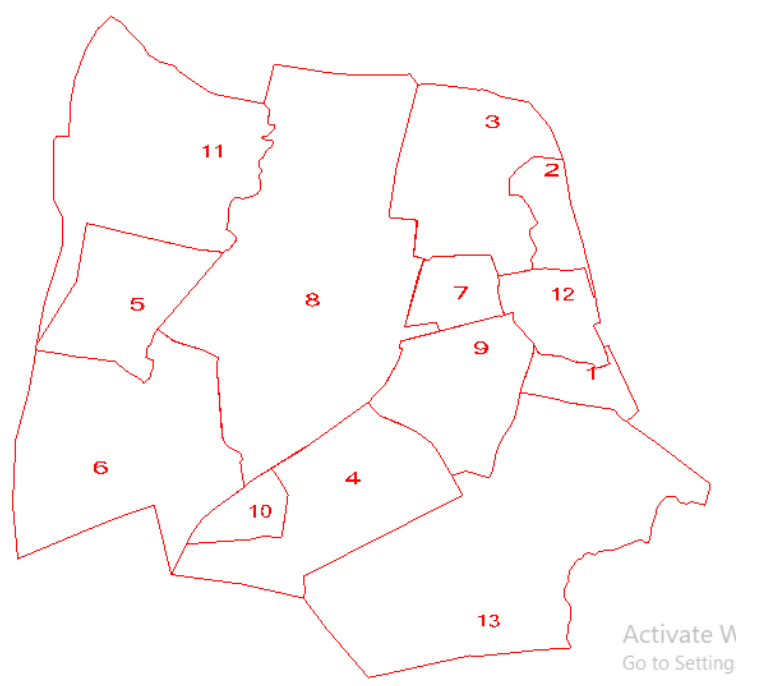

Fig 1 Zone Formation in Pandharpur City

For this particular paper detail case of Ambika nagar zone i.e. zone 2 is taken. Primarily from the population forecasting data available for Pandharpur city from 2011 is taken to calculate the population for immediate stage, intermediate stage and ultimate stage. Based on the time lag between project design and completion, which is assumed not to exceed two years, design period for this work was adopted. This is as shown below:

Immediate stage: - 2015

Intermediate stage: - 2030

Ultimate stage:-2045

Demand for each stage is calculated and for immediate stage 1.44MLD, for intermediate stage 1.80MLD and for ultimate stage it is 2.22 MLD. Using load distributor in Water GEMS software network is designed to convert existing water supply system into to $24 x 7$ for Ambika Nagar Zone -2 in Pandharpur city as shown in fig 2 . Where the pipe network shown in brown colour is an existing network

where pipe network shown with black is a proposed one to meet demand of ultimate stage as shown in fig 3.

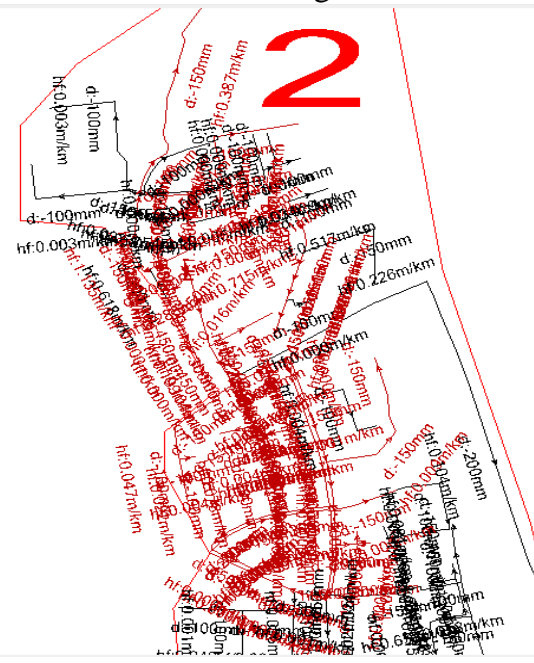

Fig 2 Existing WSS in Ambika Nagar Zone- 2

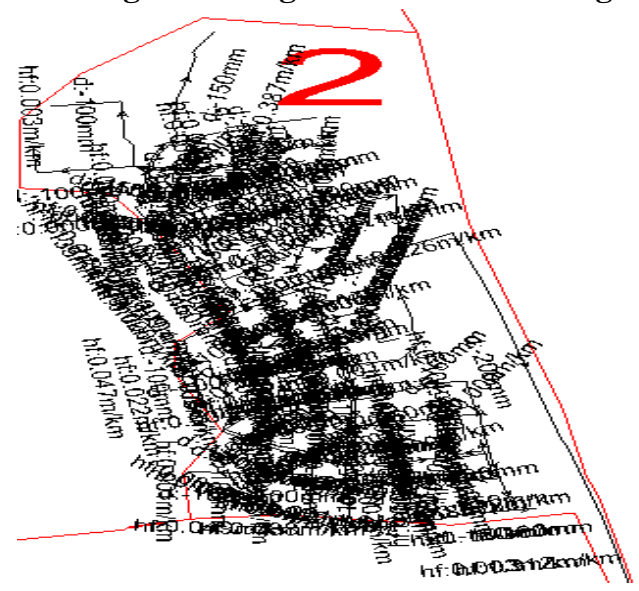

Fig 3

Proposed WSS in Ambika Nagar zone- 2

\section{ANALYSIS OF PROPOSED WATER SUPPLY SYSTEM (PWSS)}

By using graphical interface of water GEMS software, water supply network is designed for the Ambika Nagar zone 2 which will meet the demand of ultimate stage. Different diameter and material of pipe are used to design PWSS. Fig 4 shows the diameter of pipe and fig 5 shows material of pipes used in PWSS and colour legends used as shown in table 1 :

Table1: Colour Legends used in PWSS for different

\begin{tabular}{|l|l|l|l|l|}
\hline $\begin{array}{l}\text { Sr. } \\
\text { No. }\end{array}$ & Colour & $\begin{array}{l}\text { Pipe } \\
\text { Diameter }\end{array}$ & $\begin{array}{l}\text { Pipe } \\
\text { Material }\end{array}$ & $\begin{array}{l}\text { Head loss } \\
(\mathrm{m} / \mathrm{km})\end{array}$ \\
\hline 1 & Green & 100 & $\begin{array}{l}\text { Cast Iron } \\
(\mathrm{CI})\end{array}$ & $<=5$ \\
\hline 2 & Red & 150 & & \\
\hline 3 & Blue & 200 & $\begin{array}{l}\text { Ductile Iron } \\
\text { (DI) }\end{array}$ & $<=10$ \\
\hline 4 & Pink & 250 & & \\
\hline 5 & Sky Blue & 300 & & \\
\hline 6 & $\begin{array}{l}\text { Bottle } \\
\text { Green }\end{array}$ & 450 & & \\
\hline
\end{tabular}

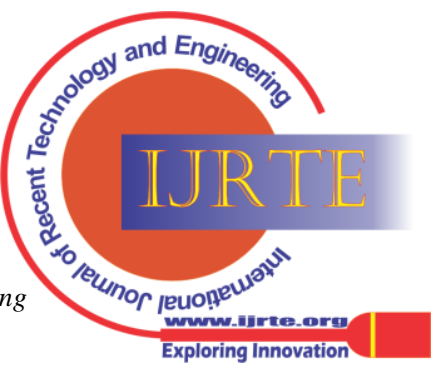




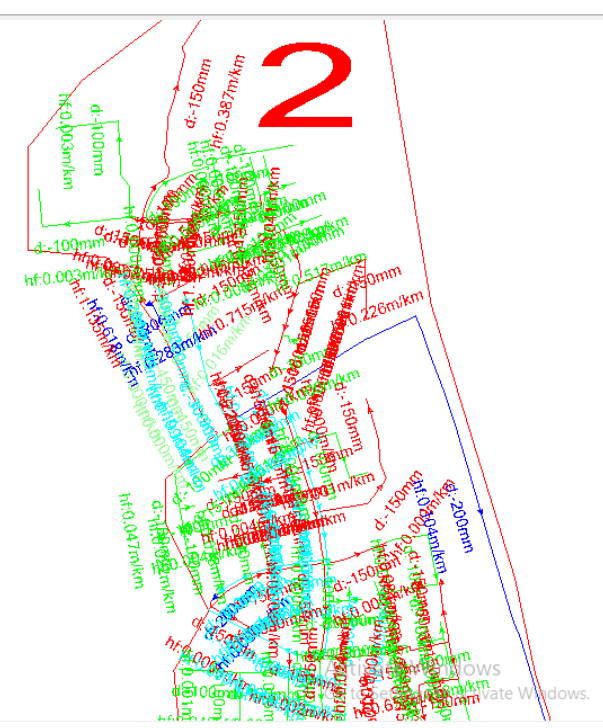

Fig 3 Diameter of pipes in PWSS

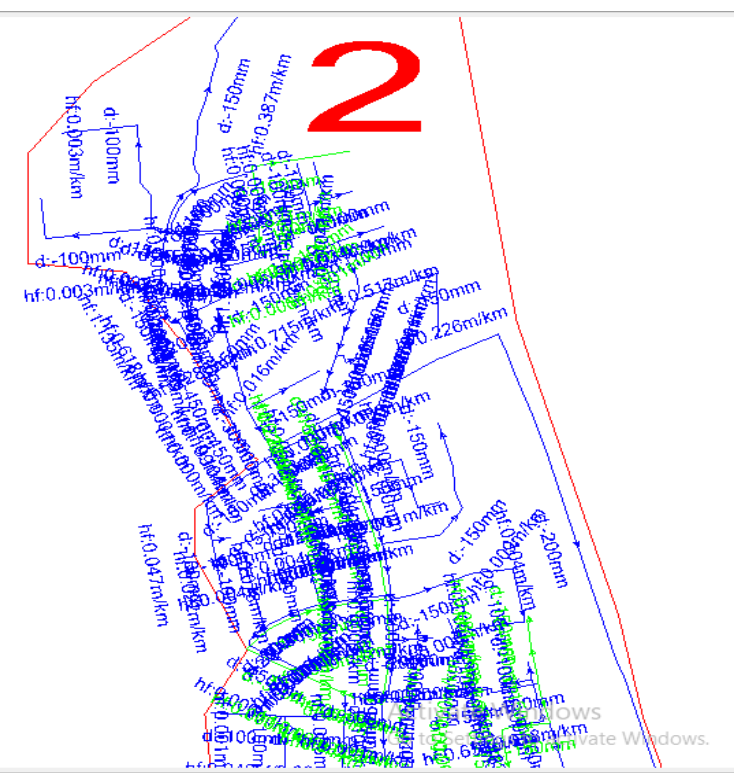

Fig 4 Pipe Material used in PWSS
In Pandharpur city buildings can be constructed up to the 3 storey as per the building byelaws. CPHEEO suggest for the building up to 3 storeys water pressure into the water supply network should be more than $14 \mathrm{~m}$ of $\mathrm{H} 2 \mathrm{O}$ for uninterrupted water supply. Also it is recommended that head loss should be minimum in WSS. Hence to achieve this goal network should be properly designed. After designing PWSS network analyzed in Water GEMS software, pressure and geadloss results are obtained as per the requirement. Fig 5 shows the head loss in pipe network while fig 6 shows the pipe pressure in network which is more than $14 \mathrm{~m} \mathrm{H} 2 \mathrm{O}$ for every pipe. $\mathrm{X}$ - axis represents the no of pipes and $\mathrm{Y}-$ axis pressure in $\mathrm{m} \mathrm{H} 2 \mathrm{O}$ in fig 6.

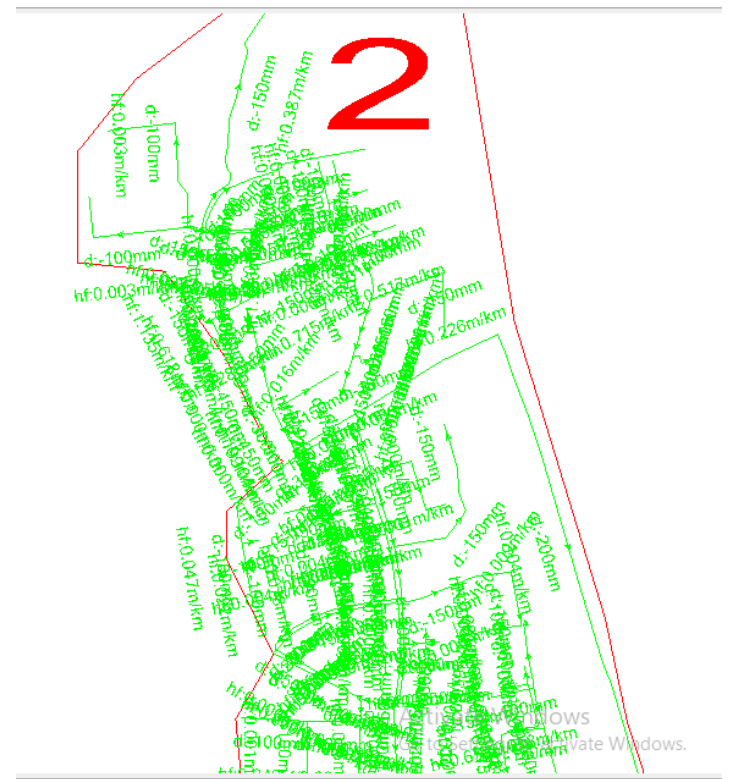

Fig 5 Head loss in PWSS

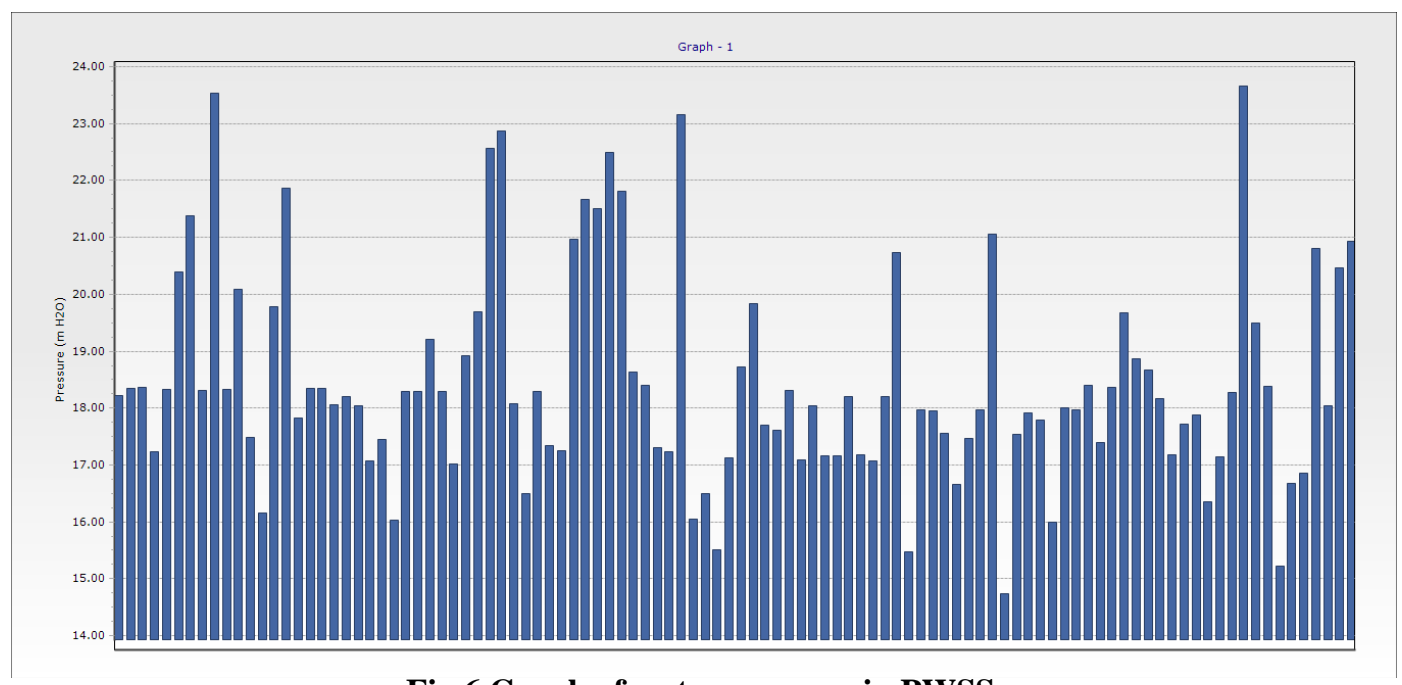

Fig 6 Graph of water pressure in PWSS

Published By:

Blue Eyes Intelligence Engineering

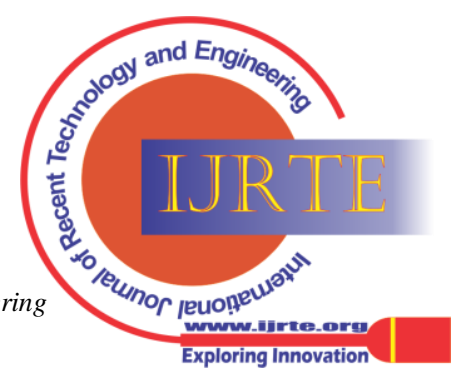


As pressure is well between the limit PWSS can be used on site. But now the question is about whether it is economical to construct. To find that out cost of the network is determined. For that, Length of the each diameter of pipe is calculated as shown in fig 7. By using price given in DSR, Pune region cost is determined which is Rs. 1,99,119.

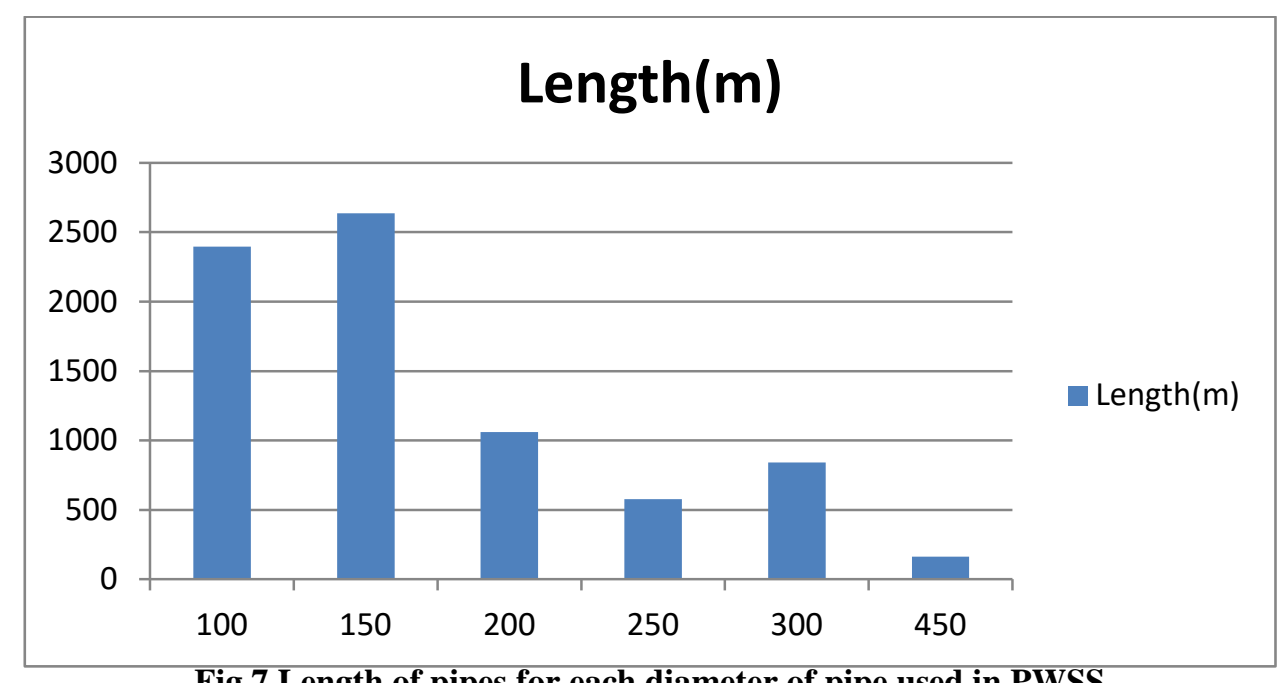

Fig 7 Length of pipes for each diameter of pipe used in PWSS

\section{OPTIMIZATion OF PWSS USING DARWIN DESIGN APPROACH}

A WaterGEMS software module called' Darwin Architect' is used to get maximum benefit from water supply network. Darwin Designer is an efficient method for the creation of new pipe architectures and programs for pipe rehabilitation. It enables network design in a more automated fashion, either manually or with efficient genetic algorithms, for an existing model. It also allows for the introduction of various concepts so as to find the best possible solution. Solutions for use in an existing water network may also be exported into a new scenario. This software optimizes the water supply network based on different constraints viz. Pressure range, flow speed etc. This module is based on a generic algorithm that makes multi-objective optimization possible. Objective function in this paper is to minimize costs for all three phases. The various optimized solutions are provided by correctly ranked software. This paper studies optimized cost condition with different pipe diameters.

After Darwin analysis three solutions are provided by software to optimize a network. In that solution cost of construction of PWSS also given as shown in fig 8. For solution 1 construction cost is observed as Rs. 173180.6; for solution 2 Rs. 173380 and for solution 3 Rs. 173553.1.

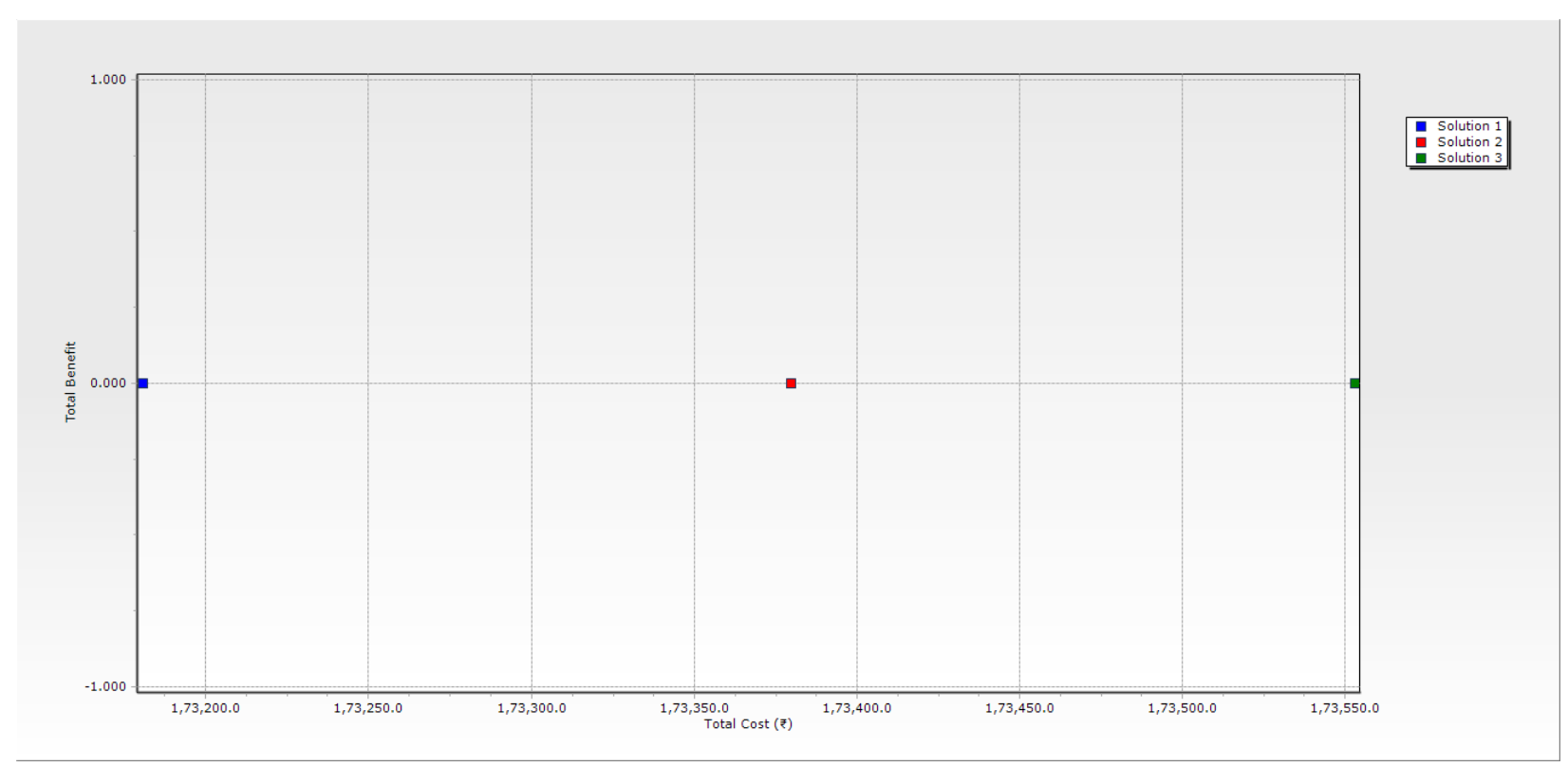

Fig 8 Total Cost of individual 3 solutions given by Darwin Designer

Published By:

Blue Eyes Intelligence Engineering

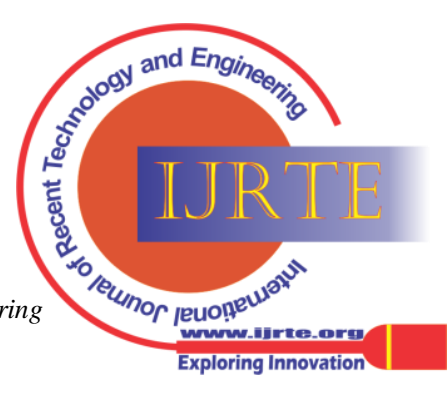




\section{RESULTS AND DISCUSSION}

It is observed that pressure of PWSS is well above the defined limit of $14 \mathrm{~m}$ H2O. Hence we can construct the PWSS on site. The cost minimization can be done by optimizing network using Darwin Designer in Water GEMS software. When cost comparison of the manual PWSS and PWSS from Darwin designer as shown in fig 9 , it is observed that solution 1 is the best feasible solution. By using this method cost up to $14 \%$ minimized. If we apply these results on broader aspect for entire 13 zones of pandharpur city it is observed that $50 \%$ cost of the manual PWSS minimized by using Darwin optimization in Water GEMS.

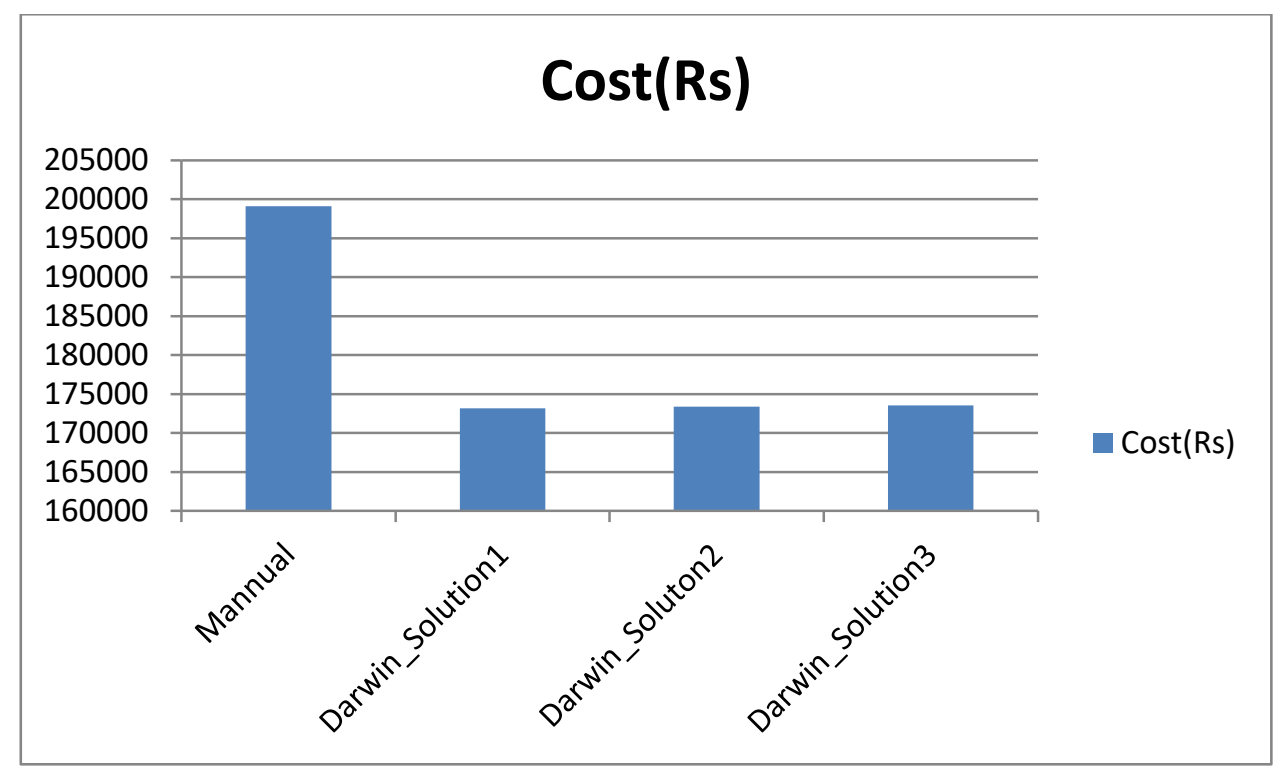

Fig 9 Cost comparison of manual and optimized PWSS

\section{CONCLUSION}

This research performs the architecture for $24 \mathrm{X} 7$ water supply, modeling, and network system optimization. Initially manual research for one zone is conducted by predicting the population and their demand. Based on this study, the effect of population on demand, head loss gradient and pressure development is carried out. Using Darwin approach, further optimization of the same network is conducted. The goal was to reduce pipe network costs. The following conclusions are summarized based on study. From the study of Darwin optimization, it is observed that the cost of the pipe network is reduced by 14 per cent with the reduction of the pressure development by balancing it at different locations.

\section{AUTHORS PROFILE}

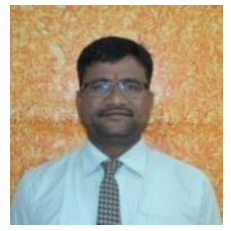

Mukund M. Pawar, Research Scholar, WIT, Solapur Associate Professor, SVERI's College of Engineering, Pandharpur

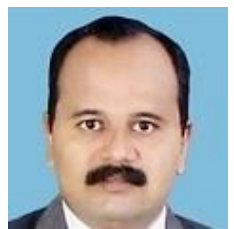

Dr. Nitin Sonaje, Principal at Government Polytechnic Miraj (Sangli), Maharashtra Formar Principal, Government Polytechnic Gadchiroli, Maharashtra (India). Deputy Registrar, Shivaji University, Kolhapur, Maharashtra.

Registrar, Solapur University, Solapur.

\section{REFERENCES}

1. Pravinkumar Shinde, Prashant Patil and Rahul Hodage, "Design and analysis of Water Distribution Network Using Water GEMS," IJARSE, Volume No. 7, Special Issue No. 3, April 2018.

2. Hamada M. Water supply system: planning aspects. Critical urban infrastructure handbook, 11, Boca Raton: CRC; 2014.

3. Gustavo Meirelles Lima, Bruno MeloBrentan, EdevarLuvizotto Jr. "Optimal design of water supply networks using an energy recovery approach"Renewable Energy 117 (2018) 404e413.

4. T.M. Walski, A history of water distribution, J. Am. Water Works Assoc. 98 (3) (2006) 110e121

5. Gustavo Meirelles Lima, Bruno MeloBrentan, EdevarLuvizotto Jr. "Optimal design of water supply networks using an energy recovery approach"Renewable Energy 117 (2018) 404e413].

6. Central Public Health and Environmental Engineering Organization (CPHEEO)

7. M.M.Pawar and N.P.Sonaje, "Optimal Design of Pipe Network for Converting Existing Network into 24x7 Water Supply System Network," International Journal of Civil Engineering (IJCE ); VOL9, ISSUE-1; Dec-Jan2020



